\title{
La RIEMS y las tutorías débiles e insuficientes para atender problemas de jóvenes preparatorianos
}

Salvador Camacho Sandoval

Fecha de recepción: 06 de noviembre de 2019 Fecha de aceptación: 17 de febrero de 2020

Resumen

$\mathrm{E}$ 1 objetivo del artículo es dar a conocer un conjunto de problemas de diversa índole que presentan los estudiantes de escuelas públicas de educación media superior en Aguascalientes, pero que pueden ser comunes a otras en varios estados del país, mismos que no son fáciles de resolver a través de las tutorías ofrecidas en dichas escuelas. La descripción de esta problemática y el reconocimiento de la incapacidad de atención son producto de la opinión de directivos, tutores y profesores, quienes fueron consultados a través de la aplicación de cuestionarios y entrevistas a profundidad en 2018. Se concluye que, frente a la magnitud de los retos educativos -que también son familiares y sociales-, las tutorías deben estar acompañadas de un trabajo de colaboración directo y eficaz por parte de maestros y padres de familia, así como de personas responsables de instrumentar programas sociales a favor de los jóvenes fuera de la escuela.

Palabras clave: problemática juvenil, tutoría, educación media superior

\section{Introducción}

En una exploración sobre la problemática de los jóvenes que estudian en bachilleratos públicos de Aguascalientes, entre 2018 y 2019, se encontraron problemas graves, que van desde la pobreza económica de muchas familias hasta el consumo de estupefacientes y la violencia física en estudiantes de este nivel educativo (Camacho, 2019) ${ }^{1}$. Desde la aplicación de la Reforma Integral de la Educación Media Superior (RIEMS) en 2008, se puso como un objetivo prioritario atender no sólo contenidos académicos y elevar el nivel de aprovechamiento, sino

1 Esta investigación fue apoyada por el Instituto Nacional para la Evaluación de la Educación y el Consejo Nacional de Ciencia y Tecnología (CONACyT). también atender la vinculación que existe, o debe existir, entre la preparación de los estudiantes y su entorno sociocultural, económico y político, como parte de su formación integral (SEP, 2008). Además de que la educación se concibe como derecho básico que debe estar presente en toda política educativa (Latapí, 2009).

Investigadores reconocen que la calidad educativa no solamente se basa en la obtención de indicadores altos de aprovechamiento escolar, sino en la correspondencia que existe entre la educación impartida y las condiciones sociales en las que viven los alumnos y sus familias; mencionan que, de no ser así, la educación que se imparta a los jóvenes preparatorianos será "irrelevante". En este mismo sentido, también hay un reconocimiento de que, si 
los contenidos de los planes de estudio no están relacionados con las inquietudes, necesidades y aspiraciones de los estudiantes, tampoco hay calidad educativa, por más que éstos obtengan buenas calificaciones (INEE, 2007). De esta perspectiva vale preguntarse: si los contenidos no son pertinentes para los alumnos ni relevantes para lo que requiere la sociedad, entonces ¿qué sentido tiene aprenderlos?

《i los contenidos de los planes de estudio no están relacionados con las inquietudes, necesidades y aspiraciones de los estudiantes, tampoco hay calidad educativa, por más que éstos obtengan buenas calificaciones. 》〉

La RIEMS finalmente se aplicó con la creación del Sistema Nacional del Bachillerato (SNB) (SEP, 2008) y logró trascender los sexenios; en cambio, la reforma educativa -impulsada por Enrique Peña Nieto desde 2013- fue rechazada por el gobierno de Andrés Manuel López Obrador y abrogada por la nueva legislatura. Esto no significa que la RIEMS continúe con el impulso que tuvo inicialmente, porque es perceptible su debilidad y las dificultades para incorporarse a las nuevas circunstancias y exigencias.

La formación integral del estudiante mexicano en todos los niveles educativos está considerada en leyes nacionales y en programas educativos gubernamentales. Así se estipuló, por ejemplo, en el modelo educativo impulsado a fines del pasado sexenio (2012-2018), el cual señalaba que era muy importante contar con "aprendizajes clave para la formación integral" de las personas. El reto educativo, se dijo, era "preparar a nuestros hijos e hijas para que puedan afrontar el difícil momento histórico que están viviendo y logren realizarse plenamente". Este desafío sigue siendo mayúsculo, puesto que, según la autoridad educativa, no sólo se trata de "cambiar la vida de las personas, sino de transformar algo mucho más grande: México" (SEP, 2017b, p. 3).

De manera específica, la educación media tiene el compromiso de hacer los cambios en esta dirección, para lo cual todos los actores involucrados en estas escuelas tienen que asumir nuevas res- ponsabilidades, pues no se pueden lograr objetivos ambiciosos siguiendo los mismos caminos y teniendo las mismas herramientas. De manera particular, los tutores ocupan un lugar sobresaliente, tal como se ha reconocido y se expresó con la creación del Sistema Nacional de Tutorías Académicas (SINATA), el cual se presenta como:

Una estrategia para contribuir al desarrollo de las competencias y apoyar a los alumnos en la resolución de problemas de tipo académico; coadyuvar en la promoción de su autonomía y formación integral, así como contribuir a mejorar su rendimiento académico mediante la adecuada orientación personalizada y de grupo (SEP, 2011, p. 7).

Si bien, el énfasis se pone en el área académica, también se prioriza la "formación integral", sobre todo si se considera que el Marco Curricular Común de la educación media superior, de manera específica, tiene un apartado sobre "habilidades socioemocionales" y el apoyo para que los jóvenes conciban responsablemente un proyecto de vida. Estas habilidades tienen que ver, entre otras características, con "entender y regular sus emociones, establecer y alcanzar metas positivas [...], establecer relaciones interpersonales armónicas, tomar decisiones responsables y desarrollar sentido de comunidad" (SEP, 2017b, p. 853).

\section{Metodología}

La investigación tuvo objetivos generales tendientes a conocer cómo se aplica la RIEMS -la reforma educativa del gobierno de Peña Nieto-, y fue a partir de los resultados de este estudio como se logró identificar un conjunto de problemas de los estudiantes de bachillerato y reconocer la incapacidad que tienen tutores y asesores que laboran en estas escuelas. Para realizar dicha exploración se hizo un estudio Delphi y se realizaron entrevistas a directores y profesores de bachilleratos de Aguascalientes. Cabe señalar que el estudio Delphi aplica cuestionarios en varias ocasiones para afinar opiniones de "expertos", por lo que es usada para identificar asuntos complejos y hacer propuestas de política pública (Turoff y Linstone, 2002). 


\section{Resultados}

En el estudio Delphi, los encuestados distinguen problemas escolares, como la deserción, el bajo aprovechamiento, la falta de infraestructura y equipamiento y, entre otros, "el exceso de distractores"; pero también identifican problemas que trascienden las aulas, como las adicciones, la violencia y los embarazos no deseados. Al mismo tiempo, varios de ellos reconocen las dificultades e incapacidad que tienen tutores y asesores para dar respuestas eficaces a estas problemáticas, aunque insisten en su importancia. Mencionan que las reformas educativas "han puesto atención en el desarrollo socio-afectivo de los estudiantes", y que "los tutores y orientadores se incorporaron al trabajo escolar promoviendo mejores resultados académicos" e impulsando una formación más integral en los estudiantes. Sin embargo, también señalan que existe "vaguedad en los cómos", donde los problemas son tan grandes que ellos solos no pueden resolverlos. En este sentido, se tuvo consenso en señalar que "la descomposición social afecta a los procesos formativos que pretenden desarrollarse en la escuela", pues -frente a estas dificultades de carácter estructural- lo que hacen los tutores resulta insuficiente. Textualmente, se reconoce que "falta impacto de tutorías en el estudiante con su entorno" y "falta el apoyo de la psicología para la canalización efectiva del estudiante".

《 La descomposición social afecta a los procesos formativos que pretenden desarrollarse en la escuela, frente a estas dificultades de carácter estructural, lo que hacen los tutores es insuficiente. Se reconoce que falta impacto de las tutorías en el estudiante con su entorno y el apoyo de la psicología para la canalización efectiva del estudiante. \>

En entrevistas a profundidad, los problemas de los estudiantes fueron mencionados de manera recurrente por directores, tutores y profesores, así como la urgencia de atenderlos para cumplir con su "formación integral". Uno de ellos dijo que los padres de familia no ponen de su parte y hacen que los problemas crezcan, así, por consecuencia, no existe el aprovechamiento escolar que se espera de los estudiantes. Un director del subsistema Centro de Estudios Científicos y Tecnológicos (CECYT) dijo: "la primera escuela es la casa y batallamos mucho para que haya ese apoyo por parte de los padres de familia" (Entrevistado 1, comunicación personal, 21 de mayo de 2018). Otro profesor señaló que se ha incrementado el número de embarazos y que el problema "ahora es mucho más grave" (Entrevistado 2, comunicación personal, 24 de mayo de 2018). Según las estadísticas, ciertamente, este fenómeno es real, ya que "en México dos de cada diez embarazos se dan en adolescentes" (La Jornada, 2018). Se sabe que existe una relación significativa entre el mundo de las emociones y los resultados académicos (Zavala, 2019).

Estos y otros problemas han sido tomados en cuenta en programas de educación media superior. Uno de ellos es "Construye T", el cual atiende asuntos juveniles que trascienden el mundo académico, pero que también han llegado a burocratizarse y no cumplen con los objetivos para los que fueron creados. ${ }^{2}$ La idea es que los profesores $-\mathrm{y}$ no sólo los tutores- se comprometan con la solución de dificultades, aunque uno de ellos pregunta: "¿o le quito a los contenidos de las materias o le doy espacio a los contenidos socioemocionales?" (Entrevistado 3, comunicación personal, 15 de junio de 2018). A su llegada al puesto, la directora general del Colegio Nacional de Educación Profesional Técnica (CONALEP) en el estado se percató de que había drogadicción, violencia y embarazos entre los estudiantes, mismos que no estaban siendo atendidos, por lo que contrató a tutores especializados para que estuvieran presentes en todos los planteles del CONALEP, sin esperar a que la Secretaría de Educación Pública los apoyara. Con este personal de confianza, elaboró un programa y se pusieron a trabajar; después de tres años pudieron observar cambios positivos, a pesar de reconocer que faltaba mucho por hacer (Entrevistado 4, comunicación personal, 24 de junio de 2018).

2 El que esto escribe fue director de Educación Media Superior y Superior en el Estado de Aguascalientes (2010-2013) y tiene conocimiento de la aplicación de este programa. 


\section{Consideraciones finales}

Los participantes en el estudio Delphi y los entrevistados coinciden en visibilizar la magnitud de los problemas entre los alumnos de bachillerato, pues están de acuerdo que la escuela, como comunidad educadora, tiene un papel muy importante en la resolución de los mismos; pero también hay coincidencia en señalar que es necesario crear y reforzar las tutorías.

\section{《 La política educativa en los}

bachilleratos ha puesto atención en la formación socio-afectiva desde hace unos años, y esto es visto como muy positivo, pero ante la problemática detectada, hace falta hacer más, mucho más. Las medidas gubernamentales no tendrán éxito si no se reconoce en los hechos la trascendencia del papel de estos profesionales de la educación y la participación de los padres de familia y otros actores sociales. $\boldsymbol{}\rangle$

En la mayoría de los casos se menciona que, además, es muy necesaria la participación de los padres de familia, toda vez que el contexto socioeconómico y cultural en el que viven muchos jóvenes hace muy complicado y difícil el trabajo de los tutores y asesores. La política educativa en los bachilleratos ha puesto atención en la formación socio-afectiva desde hace unos años, y esto es visto como muy positivo, pero ante la problemática detectada, hace falta hacer más, mucho más. Las medidas gubernamentales no tendrán éxito si no se reconoce en los hechos la trascendencia del papel de estos profesionales de la educación y la participación de los padres de familia y otros actores sociales.

El ejercicio de recuperar las opiniones y valoraciones de maestros y directivos sobre la problemática de la formación de jóvenes preparatorianos se hace a la luz de la obligatoriedad de la educación media superior y de un nuevo gobierno que derogó una reforma educativa y dejó la RIEMS. El interés gubernamental manifiesto es atender la cobertura y evitar la deserción, pero poco se habla de mejorar la calidad educativa y resolver la problemática social y familiar que llega todos los días a estas escuelas.

\section{Fuentes de consulta}

Camacho, S. (2019). ¿Cómo se aplica la Reforma Integral de Educación Media Superior (RIEMS) y la Reforma educativa de 2013? Evaluación desde la gestión escolar en subsistemas federales y estatales en Aguascalientes. México: CONACYT-INEE-UAA.

INEE (2007). Seminario internacional de indicadores educativos. Conceptos, metodología y experiencias para la construcción del sistema de indicadores educativos. México: INEE.

La Jornada (23/marzo/2018). Encuentro Nacional para la Prevención del Embarazo Adolescente en Aguascalientes. Recuperado de: https://bit. ly/2WFKmwP.

Latapí, P. (2009). El derecho a la educación. Su alcance, exigibilidad y relevancia para la política educativa. Revista Mexicana de Investigación Educativa, (14), 255-287.

SEP (2008). Reforma Integral de la Educación Media Superior. México: SEP.

SEP (2011). Sistema Nacional de Tutorías Académicas. México: SEP.

SEP (2017a). Aprendizajes Clave para la Educación Integral. México: SEP.

SEP (2017b). Planes de estudio de referencia del marco curricular común de la educación media superior. México: SEP.

Turoff, M. y Linstone, H. (2002). The Delphi Method Techiniques and Applications. Murray Turoff and Harold A. Linstone. Recuperado de: https://bit.ly/33uovuZ.

Zavala, G. (2019). La salud emocional y los resultados académicos. Docere, 20, 35-37.

\section{Entrevistas (por razones de confidencialidad} se omiten los nombres de los entrevistados)

Entrevista de Ana Victoria Velázquez Díaz a Entrevistado 1, Aguascalientes, Ags., 21 de mayo de 2018.

Entrevista de Salvador Camacho Sandoval a Entrevistado 2, Aguascalientes, Ags., 24 de mayo de 2018 .

Entrevista de Salvador Camacho Sandoval a Entrevistado 3, Aguascalientes, Ags., 15 de junio de 2018.

Entrevista de Salvador Camacho Sandoval a Entrevistado 4, Aguascalientes, Ags., 24 de julio de 2018. 